\title{
Twist-Bend Nematogenic Supramolecular Dimers and Trimers Formed by Hydrogen Bonding
}

\author{
Rebecca Walker ${ }^{1,2}, *\left(\mathbb{D}\right.$, Damian Pociecha ${ }^{2} \oplus$, Alfonso Martinez-Felipe ${ }^{3}{ }^{\oplus}$, John MD Storey ${ }^{1}$, \\ Ewa Gorecka ${ }^{2}$ and Corrie T Imrie ${ }^{1}$ \\ 1 Department of Chemistry, School of Natural and Computing Sciences, University of Aberdeen, \\ Scotland AB24 3UE, UK; c.t.imrie@abdn.ac.uk \\ 2 Faculty of Chemistry, University of Warsaw, ul. Zwirki i Wigury 101, 02-089 Warsaw, Poland; \\ pociu@chem.uw.edu.pl (D.P.); gorecka@chem.uw.edu.pl (E.G.) \\ 3 Chemical and Materials Engineering Group, School of Engineering, University of Aberdeen, \\ AB24 3UE Scotland, UK; a.martinez-felipe@abdn.ac.uk \\ * Correspondence: rebecca.walker@abdn.ac.uk
}

Received: 10 February 2020; Accepted: 3 March 2020; Published: 6 March 2020

\begin{abstract}
A selection of novel non-symmetric supramolecular liquid crystal dimers and trimers formed by hydrogen-bonding have been prepared and their phase behaviour characterised by polarised optical microscopy, X-ray diffraction and temperature-dependent Fourier-transform infrared spectroscopy. We mix the bent twist-bend nematogen 4-[6-(4'-cyanobiphenyl-4-yl) hexyloxy]-benzoic acid (CB6OBA) with a series of small stilbazole-based compounds 4-[(E)-2-(n-alkoxyphenyl)ethenyl]pyridines $(n \mathrm{OS})$ of varying terminal chain length $(n)$ to obtain the CB6OBA: $n$ OS complexes. Complexes with $n \leq 7$ exhibit nematic and twist-bend nematic behaviour, followed on cooling by a smectic $C$ phase for $n=4-7$, and finally, a hexatic-type smectic X phase for $n=3-7$. Mixtures with $n=8-10$ exhibit a smectic A phase below the conventional nematic phase, and on further cooling, a biaxial smectic $A_{b}$ phase and the same hexatic-type SmX phase. Supramolecular trimers, CB6OBA:CB6OS and CB6OBA:1OB6OS, formed between CB6OBA and dimeric stilbazoles [(E)-2-(4-\{[6-(4'-methoxy[1,1'-biphenyl]-4-yl)hexyl]oxy\}phenyl)ethenyl]pyridine (1OB6OS) or 4-[(E)-4'-(6-\{4-[(E)-2-(pyridin-4-yl)ethenyl]phenoxy\}hexyl)[1,1'-biphenyl]-4- carbonitrile (CB6OS), exhibit nematic and twist-bend nematic phases, and are the first hydrogen-bonded trimers consisting of unlike donor and acceptor fragments to do so.
\end{abstract}

Keywords: liquid crystals; twist-bend nematic phase; hydrogen-bonding; supramolecular liquid crystals; supramolecular dimers; supramolecular trimers; spontaneous symmetry breaking

\section{Introduction}

The experimental identification of a new nematic phase in 2011 is undoubtedly one of the most significant developments of the past decade in liquid crystal science [1]. The twist-bend nematic phase, $\mathrm{N}_{\mathrm{TB}}$, was first predicted in the mid 1970s by Meyer [2] and later, independently in 2001 by Dozov [3], who proposed that a nematic phase consisting of bent-shaped molecules would have an anomalously low bend elastic constant, $K_{33}$, compared to conventional rod-like nematogens. He considered the possibility that $\mathrm{K}_{33}$ could become negative giving a spontaneous, uniform bend of the director. However, such uniform bend is elastically impossible, and so must be accompanied by other deformations of the local director, either splay or twist, giving rise to either the splay-bend or twist-bend nematic phases [3]. In the twist-bend nematic, $\mathrm{N}_{\mathrm{TB}}$, phase, the molecules are arranged in a heliconical superstructure of nanoscale periodicity while retaining a random distribution of their centres of mass [4]. This chiral superstructure is formed despite the constituent molecules being chemically achiral, and indeed, the $\mathrm{N}_{\text {Tв }}$ phase represents the first example of spontaneous chiral symmetry breaking in a fluid system 
with no spatial ordering. As this induction of chirality is spontaneous, there exists an equal probability of the formation of either handedness of the helix, and hence, the $\mathrm{N}_{\mathrm{TB}}$ phase consists of doubly degenerate locally chiral domains of opposite handedness giving a globally achiral phase. However, the presence of intrinsic molecular chirality removes this degeneracy and the chiral $\mathrm{N}_{\mathrm{TB}}$ phase is formed [5]. In his seminal work, Dozov also predicted the formation of heliconical smectic phases [3] and examples of these have recently been reported [6-8].

The discovery of the $\mathrm{N}_{\mathrm{TB}}$ phase resulted from a comprehensive study of the liquid crystal dimer 1,7-bis-4-(4-cyanobiphenyl) heptane, CB7CB, using a range of different techniques [1]. Liquid crystal dimers consist of molecules containing two rigid aromatic mesogenic units connected by a flexible alkyl spacer, most commonly an alkyl chain $[9,10]$. In CB7CB, the mesogenic units are cyanobiphenyl and the spacer is a heptamethylene chain. CB7CB exhibits two nematic phases, at higher temperatures, a conventional nematic $(\mathrm{N})$ phase and at lower temperatures, the $\mathrm{N}_{\mathrm{TB}}$ phase [1]. The observation of the $\mathrm{N}_{\mathrm{TB}}$ phase for $\mathrm{CB7CB}$ was attributed to the bent shape of the molecule arising from the odd-membered spacer. From a chemist's perspective, understanding the molecular features influencing the formation and stabilisation of the $\mathrm{N}_{\mathrm{TB}}$ phase is of paramount importance, and allows for the design of new materials that have targeted properties. These studies have involved systematically varying the molecular structure of twist-bend nematogens and have included varying the spacer length [11,12], the nature of the link between the spacer and mesogenic groups [13-17], the structure of the mesogenic units $[18,19]$, and of the terminal substituents $[12,20-23]$. By far the greatest number of twist-bend nematogens reported so far may be described as odd-membered liquid crystal dimers having a similar molecular curvature to CB7CB. However, the $\mathrm{N}_{\mathrm{TB}}$ phase has also been observed for rigid bent-core materials [24], a hybrid bent-core-calamitic dimer [25], trimers and tetramers [26-29], a hexamer [30], and main-chain polymers [31]. The common structural feature shared by all these molecular architectures is curvature, although this is not always uniform. It is widely believed that this curvature is a prerequisite to the observation of the $\mathrm{N}_{\text {TB }}$ phase. This view has been reinforced by a generalised Maier-Saupe theory developed for rigid V-shaped molecules that has shown the twist-bend nematic-nematic phase transition temperature to be highly sensitive to the molecular bend angle [32].

An alternative approach to the design and preparation of twist-bend nematogens is the formation of supramolecular dimeric and trimeric structures assembled through hydrogen bonding in mixtures of hydrogen bond donors and acceptors $[33,34]$. This is a flexible and efficient alternative to the use of conventional synthetic methods to obtain covalently bonded molecules, and a particularly convenient way of adding functionality to a molecule in a straightforward and controllable manner. The observation of an $\mathrm{N}_{\text {ТВ }}$ phase in 4-[6-(4'-cyanobiphenyl-4-yl) hexyloxy]benzoic acid (CB6OBA) was attributed to the formation of hydrogen-bonded complexes between pairs of acids yielding bent supramolecular complexes [33]. In this system, however, there is no element of molecular recognition given that two identical molecules form the complexes. The aspect of molecular recognition was a critical factor in our design of the first twist-bend nematogens formed by unlike $\mathrm{H}$-bond donors and acceptors. These were obtained in binary mixtures of [(E)-2-(4-\{[6-(4'-methoxy[1,1'-biphenyl]-4-yl)hexyl]oxy\}phenyl) ethenyl]pyridine (1OB6OS) or 4-[(E)-4'-(6-\{4-[(E)-2-(pyridin-4-yl)ethenyl]phenoxy\}hexyl) [1,1'-biphenyl]-4-carbonitrile (CB6OS) with the $n$-alkoxybenzoic acids ( $n$ OBAs) [34]. For short $n$, the mixtures exhibited $\mathrm{N}_{\mathrm{TB}}$ and $\mathrm{N}$ phases, and on increasing $n$, a series of smectic phases appeared below the $\mathrm{N}$ phase, extinguishing the $\mathrm{N}_{T B}$ phase. These are the first examples of the formation of spontaneous chirality driven by hydrogen bonding between unlike and achiral components in a fluid system with no spatial ordering [34].

The 1OB6OS: $n$ OBA [34] and CB6OS:nOBA [35] complexes consist of short, rod-like benzoic acid fragments and a bent stilbazole-based dimer. Neither component individually exhibits the $\mathrm{N}_{\text {TB }}$ phase. Here, we reverse the hydrogen bond and report the properties of the CB6OBA: $n \mathrm{OS}$ mixtures (Figure 1). The H-bonded acceptor, CB6OBA, is now the bent-shaped template and a twist-bend nematogen, and this is complexed with small rod-like stilbazole-based molecules of varying alkoxy chain length $n$, the 4-[(E)-2-(n-alkoxyphenyl)ethenyl]pyridines, $n$ OS. In this case, the hydrogen bond donor is not 
liquid crystalline. In designing this particular system, we note that the odd-membered hexyloxy spacer has been shown to impart a sufficiently bent molecular shape to promote the $\mathrm{N}_{\mathrm{TB}}$ phase in conventional liquid crystal dimers [36], and that the hydrogen bond between pyridyl-based fragments and benzoic acids is strong enough to promote liquid crystalline complexes. Increasing the length of the terminal chain attached to the hydrogen bond donor may reveal heliconical smectic phases as well as the $\mathrm{N}_{\mathrm{TB}}$ phase [37].

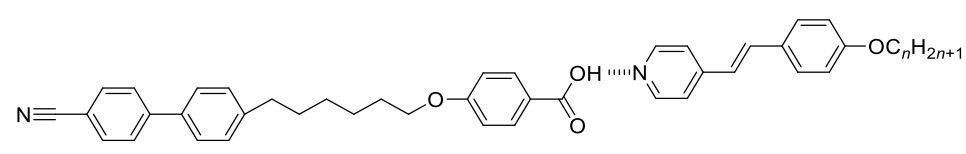

Figure 1. Structure of the CB6OBA:nOS hydrogen-bonded supramolecular dimers.

The overwhelming majority of covalently bonded liquid crystals found to exhibit the twist-bend nematic phase have been low-molar-mass dimers. A current active area of research is the investigation of $\mathrm{N}_{\mathrm{TB}}$ phase formation by trimers, higher oligomers and polymers, with an increasing number of successful studies recently published $[28,30,31,38,39]$. As described earlier, CB6OBA was the first example of a supramolecular trimer capable of exhibiting the $\mathrm{N}_{\text {Тв }}$ phase. CB6OBA can be described as a 'symmetrical' supramolecular trimer, but here, we investigate the possibility of $\mathrm{N}_{\mathrm{TB}}$ phase formation in non-symmetric hydrogen-bonded trimer complexes made up of unlike hydrogen bond donor and acceptor molecules: CB6OBA:1OB6OS and CB6OBA:CB6OS (Figure 2).

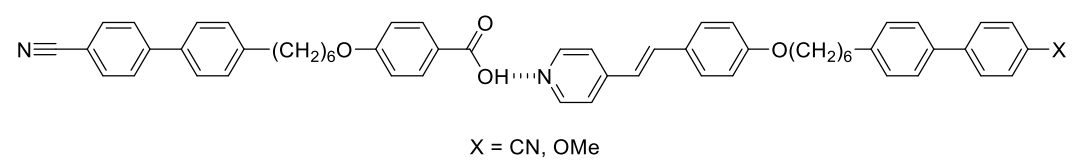

Figure 2. Structure of the CB6OBA: $m$ B6OS hydrogen-bonded supramolecular trimers, where $\mathrm{m}=\mathrm{C}$ (nitrile), 10 (methoxy).

\section{Materials and Methods}

\subsection{Synthesis 4-[6-(4'-Cyanobiphenyl-4-yl)Hexyloxy]Benzoic Acid (CB6OBA)}

CB6OBA was prepared by the procedure shown in Scheme 1, a modification to that reported previously [33]. Thus, a Friedel-Crafts acylation and subsequent ketone reduction gave 2; $\mathbf{3}$ was prepared by a Williamson ether synthesis; 4 by a modified Rosenmund-von Braun cyanation reaction, and removal of the methyl group using base hydrolysis gave $\omega$-(4'-cyanobiphenyl-4-yl)hexyloxybenzoic acid, CB6OBA 5.

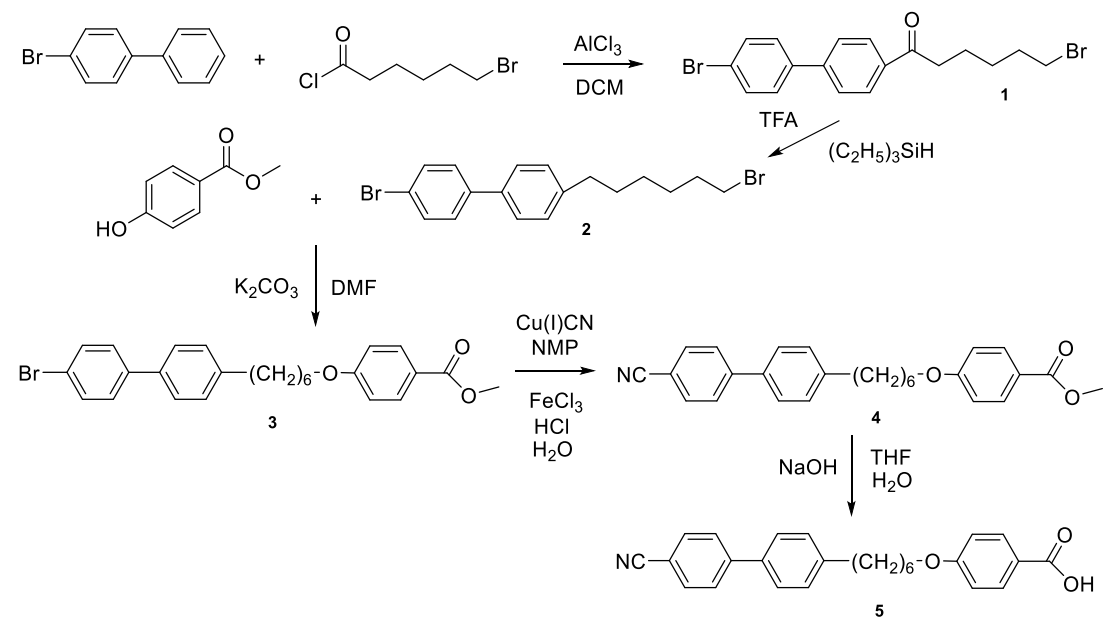

Scheme 1. Synthesis of CB6OBA. 


\subsection{Synthesis 4-[(E)-2-(4-Alkoxyphenyl)Ethenyl]Pyridines, $n O S$}

The alcoholic stilbazole 4-[(E)-2-(pyridin-4-yl)ethenyl]phenol (HOS) 6 was prepared through the base-catalysed condensation of 4-hydroxybenzaldehyde and 4-methylpyridine [40]. This was combined with the relevant $n$-bromoalkane in a Williamson ether synthesis to give the alkyl-terminated stilbazole compounds 7 , as shown in Scheme 2.<smiles>[R]Oc1ccc(/C=C/c2ccncc2)cc1</smiles>

Scheme 2. Synthesis of $n \mathrm{OS}$, where $\mathrm{R}=\mathrm{C}_{n} \mathrm{H}_{2 n+1}(n=1-10)$.

Full synthetic procedures and analytical data for all final products and their intermediates are given in the ESI.

\subsection{Binary Mixtures}

Binary mixtures were prepared by co-dissolving pre-weighed amounts of each compound in dichloromethane or chloroform and allowing the solvent to evaporate slowly at room temperature. The mixtures were further dried in a vacuum oven at $50{ }^{\circ} \mathrm{C}$ for $\sim 16 \mathrm{~h}$.

\subsection{Characterisation}

\subsubsection{Polarised Optical Microscopy (POM)}

POM measurements were performed using an Olympus BH2 polarising light microscope equipped with a Linkam TMS 92 hot stage (University of Aberdeen),or a Zeiss Axio Imager A2m polarizing microscope equipped with a Linkam heating stage (University of Warsaw). Glass cells obtained from Warsaw Military University of Technology (WAT) with thicknesses of 1.6 or 3 microns, with ITO transparent electrodes and polymer aligning layers were used.

\subsubsection{Differential Scanning Calorimetry (DSC)}

The thermal behaviour of the final products and the binary mixtures was investigated using a Mettler Toledo DSC1 differential scanning calorimeter (University of Aberdeen) equipped with a TSO 801RO sample robot and calibrated using indium and zinc standards. The heating profile in all cases, unless otherwise stated, was heat, cool and reheat at $10{ }^{\circ} \mathrm{C} \mathrm{min}^{-1}$ under nitrogen, with a 3-minute isotherm between heating and cooling segments. Thermal data were extracted from the second heating trace unless otherwise stated.

\subsubsection{X-Ray Diffraction (XRD)}

Small-angle X-ray diffraction (SAXS) patterns for powder samples were obtained with a Bruker Nanostar system using $\mathrm{CuK} \alpha$ radiation and patterns were collected with an area detector VANTEC2000 (University of Warsaw). The temperature of the sample was controlled with a precision of $\pm 0.1 \mathrm{~K}$. Samples were prepared either in thin-walled glass capillaries or as droplets on a heated surface. Wide-angle diffractograms (WAXS) were obtained with a Bruker D8 GADDS system (CuK $\alpha$ line, Goebel mirror, point beam collimator, VANTEC2000 area detector) (University of Warsaw). 


\subsubsection{Temperature-dependent Fourier Transform Infrared Spectroscopy}

Spectra were recorded on a Thermo Nicolet NEXUS 470 FT-IR spectrometer, equipped with a Linkam FT-IR 600 heating stage and a TMS 93 control unit. (University of Aberdeen) Resulting spectra were analysed using OMNIC software (Thermo Scientific). Samples were dispersed in $\mathrm{KBr}$ ( $1 \%$, by wt. of compound), ground into a fine powder and compacted at 300 bar for at least $10 \mathrm{~min}$ to yield homogeneous discs of around $1.5 \mathrm{~mm}$ thickness. Background FT-IR measurements were performed immediately prior to experiments by measuring the transmittance through a pristine $\mathrm{KBr}$ disc. For measurement of compounds, the materials were melted into the isotropic phase to remove any thermal history, and data were collected in transmittance mode on cooling to room temperature in steps of $5{ }^{\circ} \mathrm{C}$. The spectra were collected as the average of 32 scans in the $4000-400 \mathrm{~cm}^{-1}$ frequency range, with a resolution of $4 \mathrm{~cm}^{-1}$. For complex absorption bands, comprising several overlapping peaks, a peak fitting is used to determine the positions, widths, heights and areas of the underlying bands. Peak fitting is based on the original algorithm of non-linear peak fitting described by the Levenberg-Marquardt method [41].

\section{Results}

CB6OBA exhibits an enantiotropic nematic phase and a monotropic $\mathrm{N}_{\mathrm{TB}}$ phase, and the transition temperatures are in excellent agreement with those reported previously (see Table S1 in the ESI) [33,42]. None of the stilbazole-based materials, $n \mathrm{OS}$, are liquid crystalline and all melt directly into the isotropic phase at temperatures given in the ESI. The transition temperatures for the CB6OBA: $n$ OS complexes, where $n=1-10$, and the associated entropy changes are listed in Table 1. Complexes with terminal chains of length $n=1-7$ exhibit two nematic phases, $\mathrm{N}$ and $\mathrm{N}_{\mathrm{TB}}$, whereas for longer alkyl chains $\mathrm{N}_{\mathrm{TB}}$ behaviour is precluded by a series of smectic phases. The nematic phases were identified primarily based on their optical textures. For the conventional nematic phase, a schlieren texture with both two- and four-point brush disclinations was observed, and on reducing the temperature below $\mathrm{T}_{\mathrm{NTBN}}$, the schlieren pattern becomes distorted and somewhat blocky. On further cooling, a rope-like texture with coexisting areas of parabolic defects develops, characteristic of the $\mathrm{N}_{\mathrm{TB}}$ phase. Representative textures for CB6OBA:1OS are shown in Figure 3. In a planar aligned cell, a uniform texture is seen for the higher temperature nematic phase, which changes to a distinct striped pattern on cooling to the $\mathrm{N}_{\text {TB }}$ phase, see Figure 4. X-ray diffraction (XRD) studies confirm these assignments as only very weak diffuse low-angle signals were seen in the patterns for both nematic phases, indicating short-range positional ordering of the molecules.

Table 1. Transition temperatures and associated entropy changes for the CB6OBA: $n$ OS mixtures.

* Temperature obtained from DSC cooling trace. + Temperature obtained from POM. * Entropy given is a combination of overlapping exotherms corresponding to $\mathrm{SmA}-\mathrm{N}$ and $\mathrm{SmA} \mathrm{A}_{\mathrm{b}}-\mathrm{SmA}$ transition.

\begin{tabular}{|c|c|c|c|c|c|c|c|}
\hline $\mathrm{n}$ & $\mathrm{T}_{\mathrm{Cr}-} /{ }^{\circ} \mathrm{C}$ & $\mathrm{T}_{\mathrm{Sm} X} /{ }^{\circ} \mathrm{C}$ & $\mathrm{T}_{\text {SmAbSmA }} /{ }^{\circ} \mathrm{C}$ & $\mathrm{T}_{\text {SmCNTB }} /{ }^{\circ} \mathrm{C}$ & $\mathrm{T}_{\text {SmAN }} /{ }^{\circ} \mathrm{C}$ & $\mathrm{T}_{\text {NTBN }} /{ }^{\circ} \mathrm{C}$ & $\mathrm{T}_{\mathrm{NI}} /{ }^{\circ} \mathrm{C}$ \\
\hline 1 & 130 & & & & & $110+$ & 182 \\
\hline 2 & 119 & & & & & $115+$ & 190 \\
\hline 3 & 109 & $66^{*}$ & & & & $108+$ & 173 \\
\hline 4 & 108 & $70 *$ & & 86 * & & $113+$ & 180 \\
\hline 5 & 121 & $68 *$ & & 92 * & & $107+$ & 165 \\
\hline 6 & 105 & $63 *$ & & 96 * & & $106+$ & 158 \\
\hline 7 & 100 & $66^{*}$ & & 100 * & & $104+$ & 155 \\
\hline 8 & 99 & 68 * & 96 * & & 103 & & 152 \\
\hline 9 & 101 & $67 *$ & $95 *$ & & 109 & & 147 \\
\hline 10 & 105 & $72 *$ & 100 * & & 119 & & 152 \\
\hline
\end{tabular}


Table 1. Cont.

\begin{tabular}{|c|c|c|c|c|c|c|c|}
\hline $\mathbf{n}$ & $\Delta \mathrm{S}_{\mathrm{Cr}-} / \mathrm{R}$ & $\Delta \mathrm{S}_{\mathrm{SmX}-} / \mathrm{R}$ & $\Delta S_{\mathrm{SmAbSmA}} / \mathrm{R}$ & $\Delta \mathrm{S}_{\mathrm{SmCNTB}} / \mathrm{R}$ & $\Delta \mathrm{S}_{\mathrm{SmAN}} / \mathrm{R}$ & $\Delta \mathrm{S}_{\mathrm{NTBN}} / \mathrm{R}$ & $\Delta \mathrm{S}_{\mathrm{NI}} / \mathrm{R}$ \\
\hline 1 & 8.95 & & & & & - & 0.67 \\
\hline 2 & 9.64 & & & & & - & 0.94 \\
\hline 3 & 8.19 & 0.12 & & & & - & 0.89 \\
\hline 4 & 11.63 & 0.90 & & 0.23 & & - & 0.70 \\
\hline 5 & 13.51 & 0.96 & & 0.24 & & - & 0.94 \\
\hline 6 & 13.07 & 1.00 & & 0.30 & & - & 0.91 \\
\hline 7 & 13.01 & 1.11 & & 0.48 & & - & 1.02 \\
\hline 8 & 12.46 & 0.87 & $0.58 *$ & & $*$ & & 1.16 \\
\hline 9 & 13.12 & 0.52 & 0.20 & & 0.04 & & 0.67 \\
\hline 10 & 13.43 & 0.77 & 0.31 & & 0.07 & & 1.08 \\
\hline
\end{tabular}

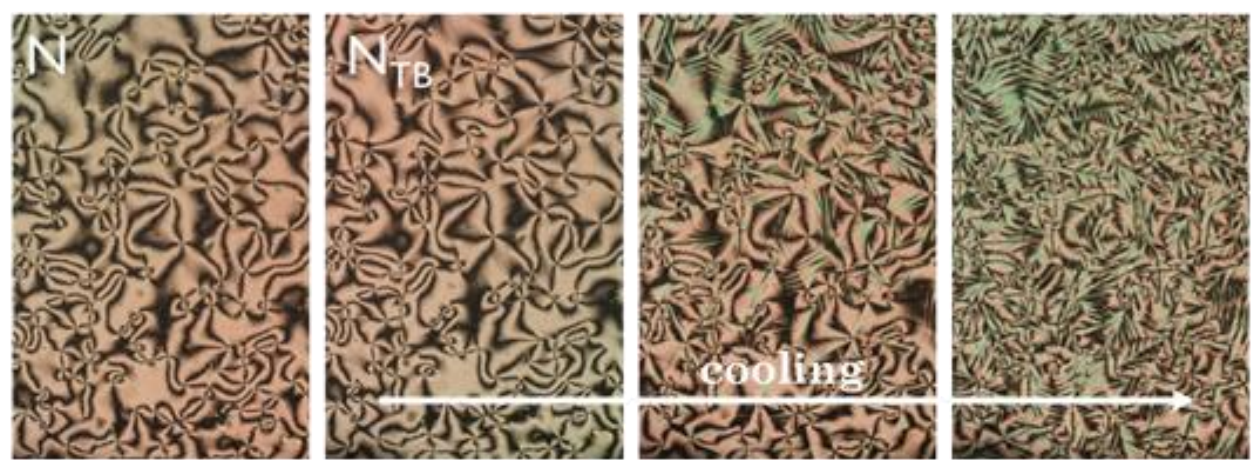

Figure 3. POM images of CB6OBA:1OS in the $\mathrm{N}$ phase (left) and showing the development of the $\mathrm{N}_{\mathrm{TB}}$ texture on cooling.
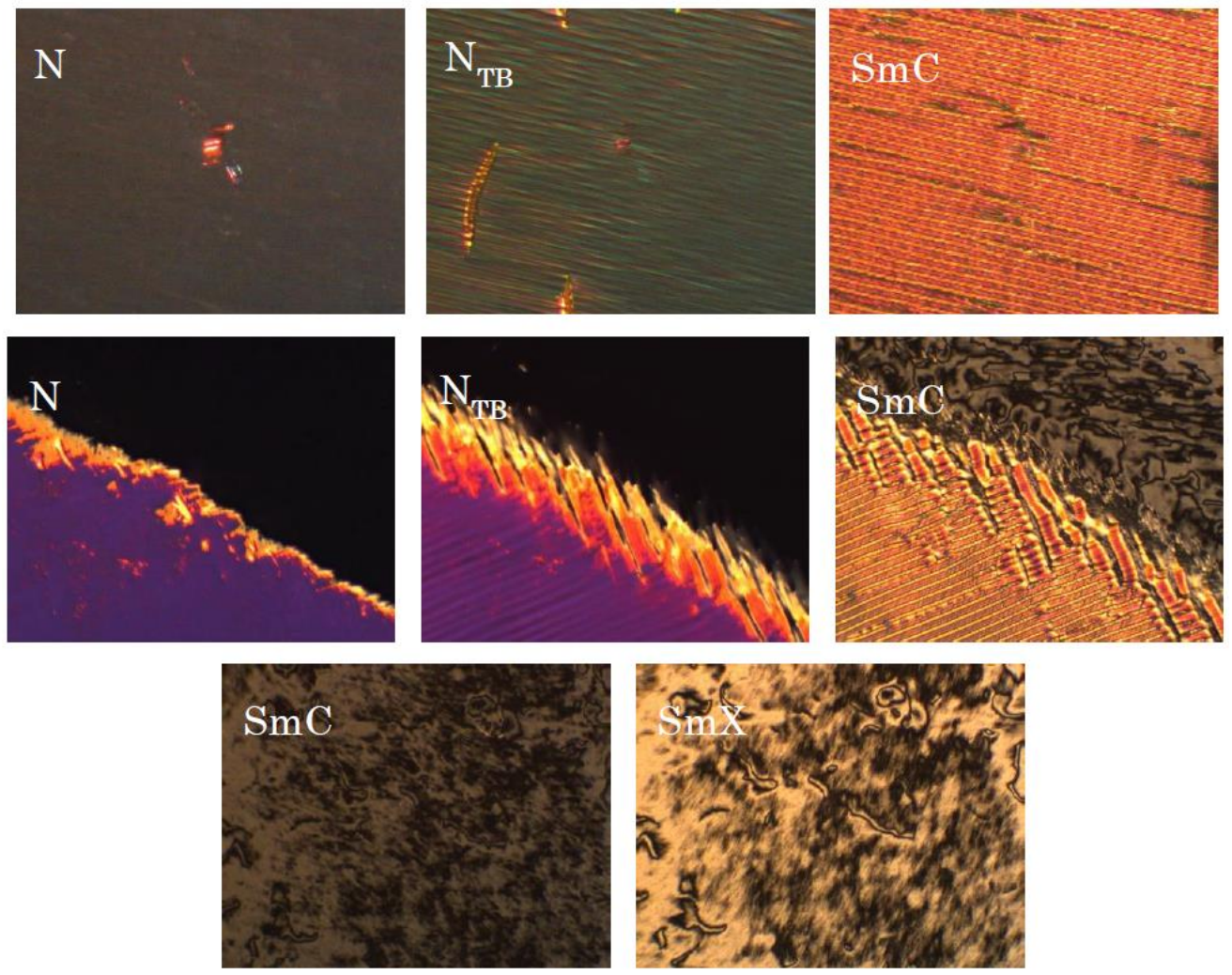

Figure 4. POM textures obtained using a planar aligned cell of 3 micron thickness for CB6OBA:4OS in the $\mathrm{N}, \mathrm{N}_{\mathrm{TB}}$ and SmC phases (top: left to right), and using glass slides with both spontaneous planar and homeotropically aligned areas in the $\mathrm{N}, \mathrm{N}_{\mathrm{TB}}, \mathrm{SmC}$, and $\mathrm{SmX}$ phases (middle and bottom). 
For complexes with $n=4-7$, further cooling results in a transition from the $\mathrm{N}_{\mathrm{TB}}$ phase to a smectic phase. The X-ray diffraction pattern of the smectic phase contains a broad, diffuse signal in the wide-angle region indicating liquid-like ordering within the layers, and a sharp small-angle signal corresponding to a periodicity of approximately the full length of the complex. Optically, the striped texture of the $\mathrm{N}_{\mathrm{TB}}$ phase is retained in the smectic phase, but the stripes become noticeably less mobile and there is a marked change in birefringence, see Figure 4. Regions of homeotropic alignment which optically appear black in the nematic phases simultaneously develop a weakly birefringent schlieren texture, see Figure 4 . The observation of a striped texture is thought to indicate a small bend elastic constant in the $\mathrm{N}_{\mathrm{TB}}$ phase, and as such, its appearance in this smectic phase strongly suggests that its bend elastic constant is also small. Such a striped texture has been observed for the $\mathrm{SmC}_{\mathrm{TB}}$ phase [8]. However, the observation of a schlieren texture is not consistent with a previously reported heliconical structure of the $\mathrm{SmC}_{\mathrm{TB}}$ phase in which directors in consecutive layers rotate according to an ideal clock model; a system in which the molecular orientations are averaged over the helix and hence a homeotropic texture is expected even though the phase is tilted [8]. Recently, however, we have observed a variant of the heliconical smectic C phase which appears to have a distorted clock structure, in which the molecular orientations are not fully averaged over the helix and hence a schlieren texture can be observed. To distinguish between a conventional $\mathrm{SmC}_{\mathrm{A}}$ phase and such a distorted-clock type smectic $\mathrm{C}_{\mathrm{TB}}$ phase, detailed resonant $\mathrm{X}$-ray diffraction studies would be required [7]. Unfortunately, in this case, the monotropic nature of the phase precludes this possibility.

For complexes with $\mathrm{n}=8-10$, the phase behaviour is quite different. The $\mathrm{N}$ phase cools first into a liquid-like lamellar phase, which is optically uniaxial, appearing as a uniformly black homeotropic texture when viewed between crossed polarisers. The sharp small-angle signal seen in the X-ray diffraction pattern again corresponds to a layer spacing of approximately the full complex length, while the high-angle signal is broad and diffuse. These observations strongly suggest a SmA phase. On further cooling, there is an emergence of a grey schlieren texture containing both two- and four-point brush disclinations, see Figure 5. The X-ray diffraction pattern of this lower temperature phase is similar to that seen for the SmA phase; however, the appearance of a second sharp signal in the low-angle region, corresponding to the 2nd harmonic of the molecular length signal, indicates an increase in the ordering of the molecules, although the high-angle signal remains broad and diffuse, see Figure 5 . Precise measurements of the variation in the layer spacing as a function of temperature are shown in Figure 6. The layer spacing sharply increases close to the Sm-Sm transition, and such an increase is indicative of a transition from the conventional $\mathrm{SmA}$ to the biaxial smectic $\mathrm{A}, \mathrm{SmA}_{\mathrm{b}}$, phase.
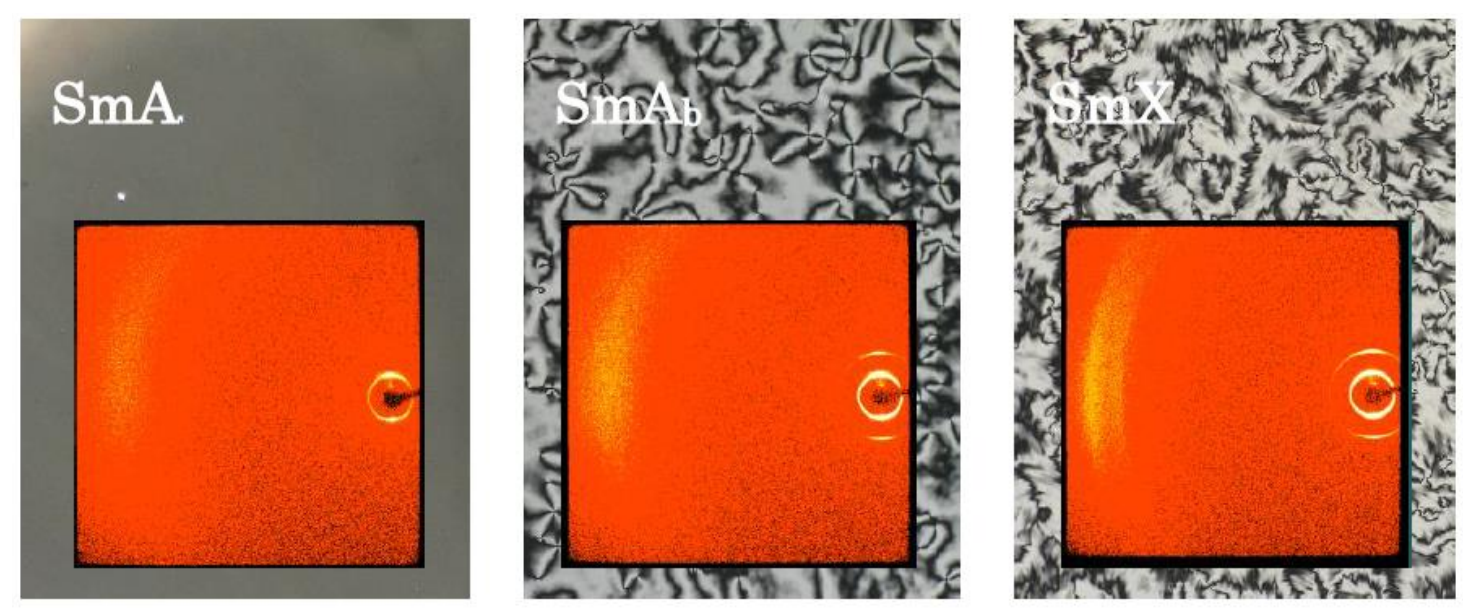

Figure 5. POM images and corresponding $X$-ray diffraction patterns obtained for CB6OBA:10OS in the $\mathrm{SmA}, \mathrm{SmA}_{\mathrm{b}}$ and $\mathrm{SmX}$ phases (left to right). 


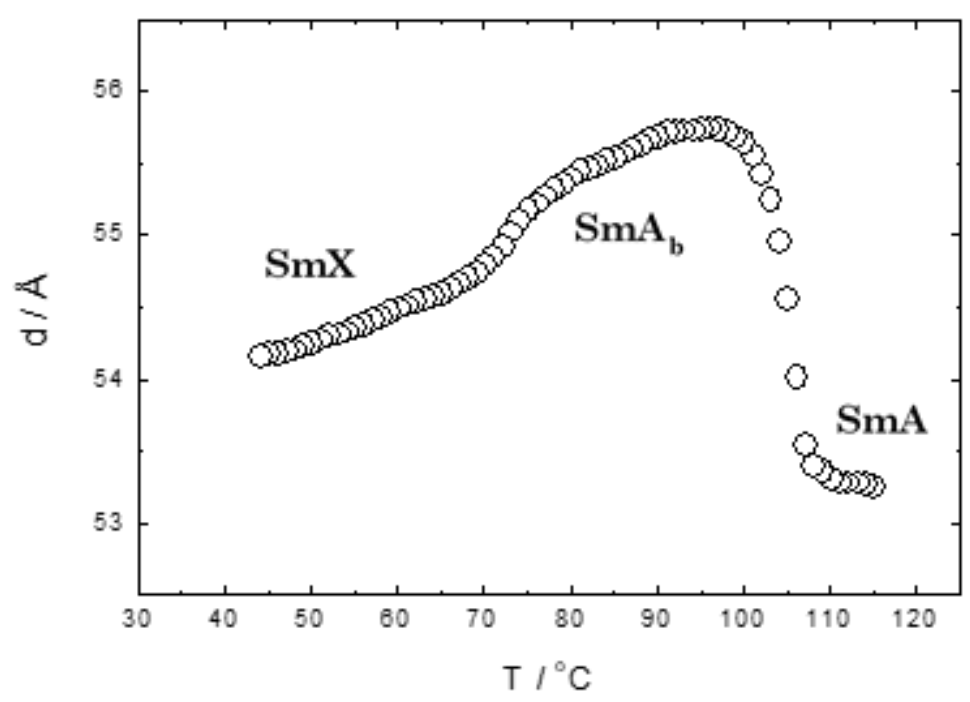

Figure 6. Dependence of layer spacing on temperature for CB6OBA:10OS.

The lowest temperature phase is present in homologues $n=3-10$ and appears optically as a heavily detailed, almost braided rope pattern if preceded by the striped textures of the $\mathrm{N}_{\mathrm{TB}}$ or SmC phases ( $n=1-7)$, or as a brighter, distorted schlieren texture on cooling from homeotropically aligned areas of the SmC phase $(n=4-7)$ or $S m A_{b}$ phase $(n=8-10)$, see Figures 3 and 4 , respectively. The reflection in the XRD pattern in the high-angle range is narrowed and splits, suggesting a tilted, hexatic smectic phase. A decrease in the layer spacing was observed on moving from both the SmC and $S m A_{b}$ phases to this lower temperature hexatic-type phase as a result of the closer packing of the molecules in this more ordered phase. X-ray diffraction results obtained for all 10 complexes are summarised in Table 2.

Table 2. Layer thickness (smectic phases) or end-to-end separation between molecules (nematic phases) and lateral spacing obtained from integrated X-ray diffraction signals for the CB6OBA: $n$ OS mixtures. For some complexes and phases, the observed pattern was too weak to determine the signal position. + Signals corresponding to full- and half-molecular length were apparent, but too weak and diffuse to integrate accurately.

\begin{tabular}{|c|c|c|c|c|c|}
\hline $\mathbf{n}$ & Phase & $\begin{array}{l}\text { Complex } \\
\text { Length/1 }\end{array}$ & $\begin{array}{c}\text { Layer Thickness/Longitudinal } \\
\text { Distance, } \mathrm{d} / \AA\end{array}$ & $\begin{array}{l}\text { Distance Between } \\
\text { Mesogens/A }\end{array}$ & $\mathrm{d} / 1$ \\
\hline \multirow{2}{*}{2} & $\mathrm{~N}$ & \multirow{2}{*}{37.8} & $12.3+$ & 4.4 & 0.3 \\
\hline & $\mathrm{N}_{\mathrm{TB}}$ & & $44.5,19.4,12.3$ & 4.4 & $1.2,0.5,0.3$ \\
\hline 3 & $\operatorname{Sm} X$ & 39.0 & $45.4,22.8,12.6$ & $4.5,4.1$ & $1.4,0.6,0.3$ \\
\hline 4 & $\mathrm{~N}_{\mathrm{TB}}$ & 40.1 & $21.6,12.8+$ & 4.9 & $0.5,0.3$ \\
\hline \multirow{4}{*}{5} & $\mathrm{~N}$ & \multirow{4}{*}{41.3} & $52.9,23.1,13.7$ & 4.5 & $1.3,0.6,0.3$ \\
\hline & $\mathrm{N}_{\mathrm{TB}}$ & & $52.6,22.9,13.6$ & 4.5 & $1.3,0.6,0.3$ \\
\hline & $\mathrm{SmC}$ & & $50.6,23.7,13.1$ & 4.3 & $1.2,0.6,0.3$ \\
\hline & $\operatorname{Sm} X$ & & $47.2,23.7,13.1$ & $4.6,4.2$ & $1.1,0.6,0.3$ \\
\hline 6 & $\mathrm{SmC}$ & 42.4 & $52.2,25.9,13.5$ & 4.4 & $1.2,0.6,0.3$ \\
\hline \multirow{3}{*}{7} & $\mathrm{~N}_{\mathrm{TB}}$ & \multirow{3}{*}{43.6} & $47.2,24.7$ & 4.4 & $1.1,0.6$ \\
\hline & $\mathrm{SmC}$ & & $52.5,26.0$ & 4.4 & $1.2,0.6$ \\
\hline & $\operatorname{Sm} X$ & & $49.6,25.8$ & $4.6,4.1$ & $1.1,0.6$ \\
\hline \multirow{3}{*}{10} & SmA & \multirow{3}{*}{47.1} & 51.9 & 4.3 & 1.1 \\
\hline & $\mathrm{SmA}_{\mathrm{b}}$ & & $53.5,27.2$ & 4.3 & $1.1,0.6$ \\
\hline & $\operatorname{SmX}$ & & $52.4,26.6$ & $4.6,4.2$ & $1.1,0.6$ \\
\hline
\end{tabular}

The dependence of the transition temperatures on the length of the terminal alkoxy chain is shown in Figure 7. The nematic-isotropic and twist-bend nematic-nematic transition temperatures decrease 
on increasing $n$, and the first five homologues exhibit a small odd-even effect with even members having the higher values. This behaviour has been observed on varying the length of a terminal chain in conventional, covalently bonded liquid crystal dimers and attributed to the change in shape anisotropy on varying the parity of $n$ giving rise to the alternation in $\mathrm{T}_{\mathrm{NI}}$ and the dilution of the interactions between the mesogenic units, which decreases $\mathrm{T}_{\mathrm{NI}}[6,22]$. Figure 7 also shows the progression of smectic behaviour as $n$ is increased revealing a distinct change occurring after $n=7$. For $n=4-7$, the $\mathrm{N}_{\mathrm{TB}}$ phase on cooling forms a SmC phase whereas for $n=8$ the $\mathrm{N}_{\mathrm{TB}}$ phase is precluded by the formation of a SmA phase on cooling the $\mathrm{N}$ phase, and on further cooling forms the biaxial $\mathrm{SmA}_{b}$ phase.

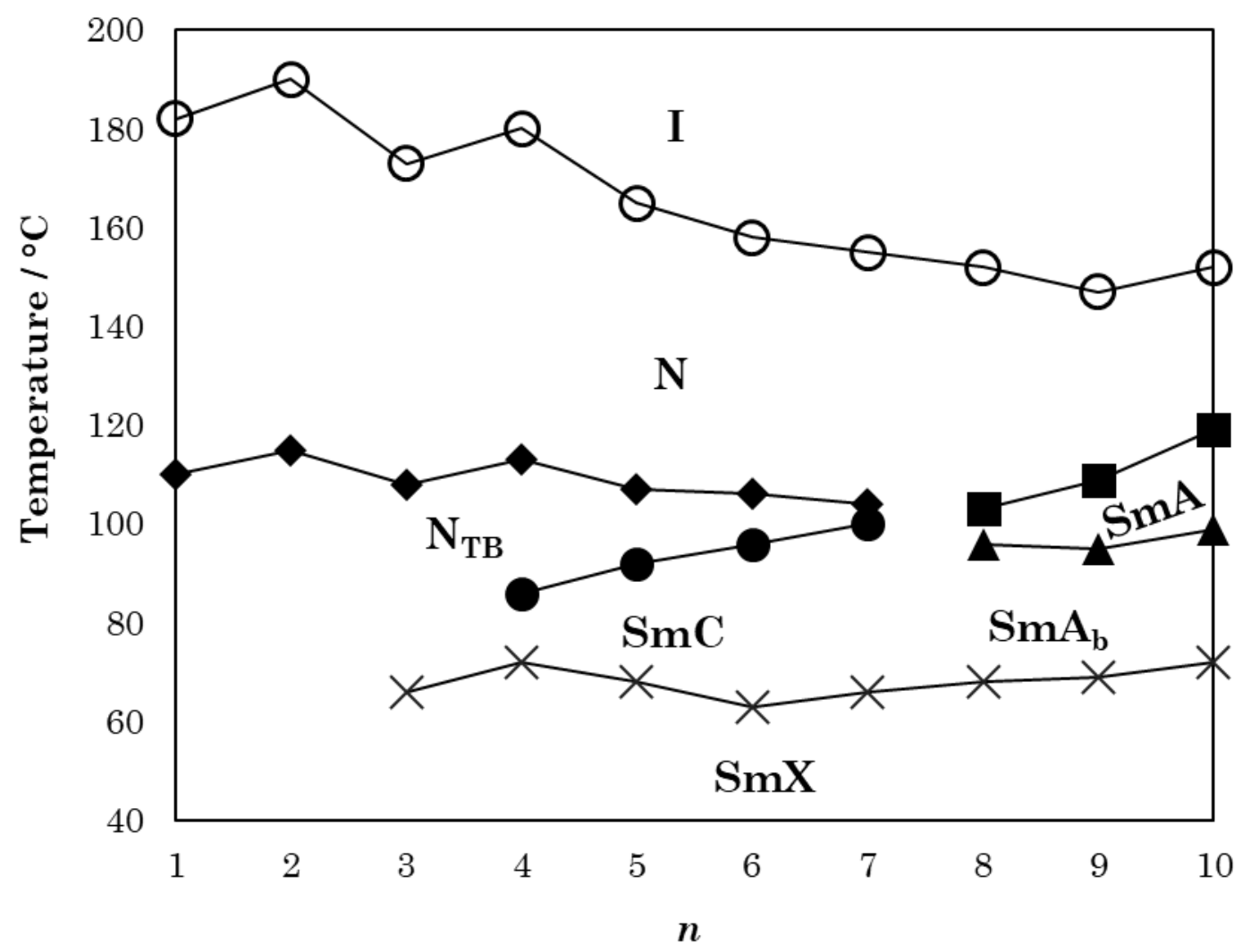

Figure 7. Dependence of phase behaviour of the CB6OBA: $n$ OS on the length of the terminal alkyl chain, $n$, where $\bigcirc$ represents $\mathrm{T}_{\mathrm{N}^{*} \mathrm{I}}, \boldsymbol{\mathrm { T } _ { \mathrm { SmAN } }}, \boldsymbol{\Delta} \mathrm{T}_{\mathrm{SmAbSmA}}, \bullet \mathrm{T}_{\mathrm{NTBN}}, \bullet \mathrm{T}_{\mathrm{SmCNTB}}$ and $\times \mathrm{T}_{\mathrm{SmXSmC} / \mathrm{Ab}}$.

Resonant X-ray diffraction was used to study the phases formed by the CB6OBA:4OS mixture. A resonant signal at the carbon edge is visible in the temperature range of the $\mathrm{N}_{\mathrm{TB}}$ phase, but was too weak to measure accurately. This resonant signal associated with the helix in the $\mathrm{N}_{\mathrm{TB}}$ phase does not appear to be temperature-dependent, but becomes even weaker on further cooling and completely disappears on heating into the nematic phase. The transition to the $\mathrm{SmC}$ phase is precluded by crystallisation of the sample, and hence, we could not establish whether this smectic $C$ phase is a further example of a heliconical smectic phase [6-8].

The FT-IR spectra obtained for the CB6OBA:4OS mixture as a function of temperature are shown in Figure 8. The observation of A-, B- and C-type Fermi bands at $\sim 2900 \mathrm{~cm}^{-1}, \sim 2700-2400 \mathrm{~cm}^{-1}$ and $\sim 1900 \mathrm{~cm}^{-1}$, respectively, indicates strong hydrogen bonding in the system (Figure 8a) [43,44]. The absence of two well-defined maxima in the B-region supports the formation of heterocomplexes between the unlike hydrogen bond donor and acceptor molecules [45]. 


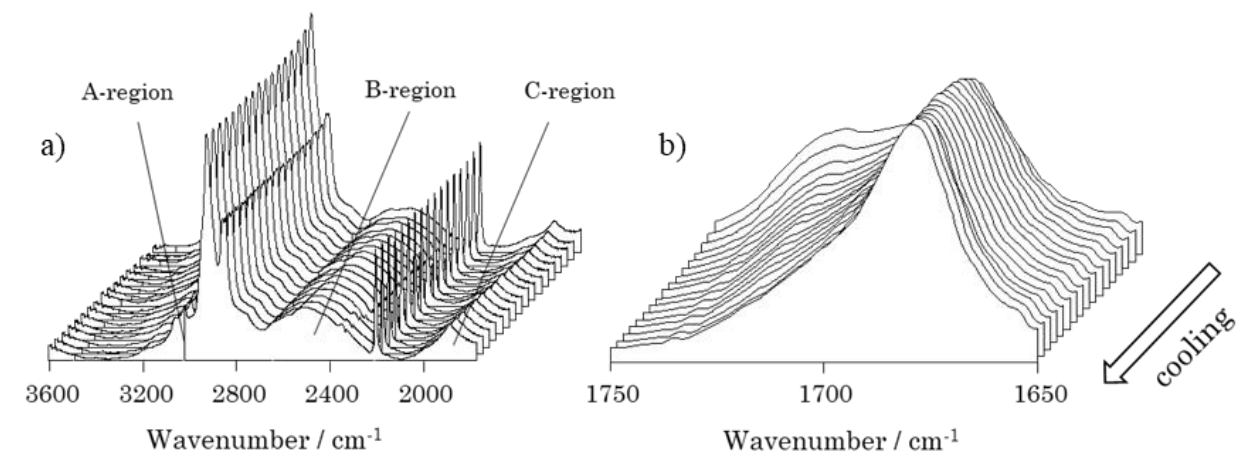

Figure 8. Temperature-dependent FT-IR spectra of the CB6OBA:4OS mixtures obtained on cooling from the isotropic melt: (a) High frequency and (b) carbonyl stretching region.

The carbonyl stretching region (1650-1740 $\mathrm{cm}^{-1}$ ) is complex, see Figure $8 \mathrm{~b}$, and contains a broad peak comprising a number of vibrations associated with the various acidic species present in dynamic equilibrium in the mixture: namely, free or monomeric benzoic acids $\left(\mathrm{C}=\mathrm{O}_{\text {mon. },} \geq 1730 \mathrm{~cm}^{-1}\right)$, asymmetric acid dimers $\left(\mathrm{C}=\mathrm{O}_{\text {asym., }} \sim 1730-1680 \mathrm{~cm}^{-1}\right)$, symmetric acid dimers $\left(\mathrm{C}=\mathrm{O}_{\text {sym, }} \sim 1680 \mathrm{~cm}^{-1}\right)$, and catemeric acid aggregates $\left(C=\mathrm{O}_{\text {cat., }} \sim 1660 \mathrm{~cm}^{-1}\right)$, see Figure 9 [46]. This region also contains the carbonyl stretching band associated with the heterocomplexes formed by the unlike acid and stilbazole-based fragments [47]. Thus, the carbonyl stretching region shown in Figure $8 \mathrm{~b}$ consists of a broad band between 1750 and $1650 \mathrm{~cm}^{-1}$, with two maxima seen for spectra collected in the isotropic phase at around 1715 and $1690 \mathrm{~cm}^{-1}$. The shape of the carbonyl stretching region indicates that the carbonyl groups are present in a range of chemical environments, and this band shape strongly resembles that reported previously for CB6OBA/pyridyl mixtures [42].

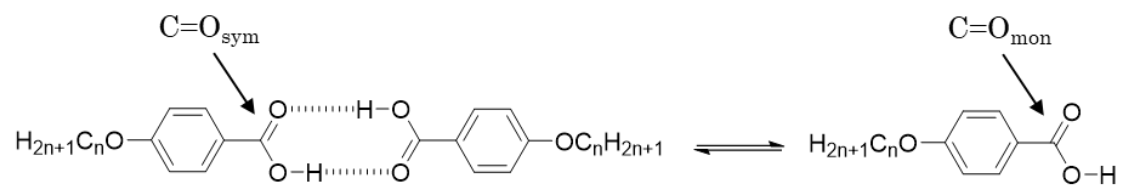

a)

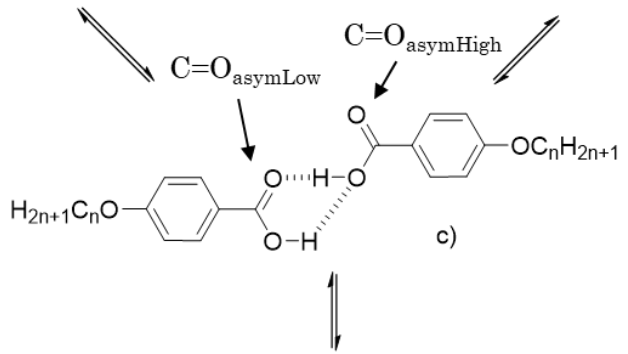

b)

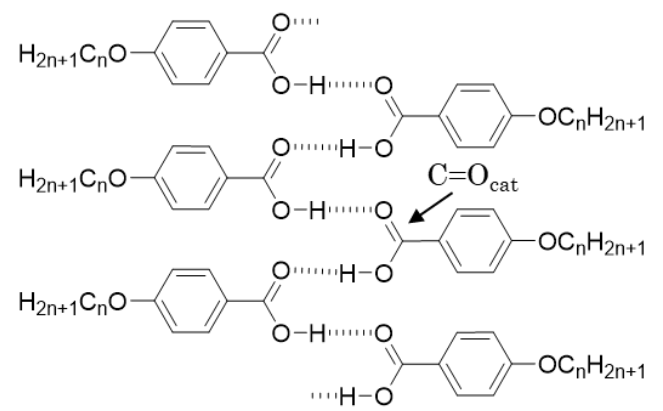

d)

Figure 9. Equilibria between the species in the alkoxybenzoic acids and the corresponding types of carbonyl groups involved, $\mathrm{C}=\mathrm{O}$ : (a) Symmetric dimers, $\mathrm{C}=\mathrm{O}_{\text {sym }}$; (b) Monomeric species, $\mathrm{C}=\mathrm{O}_{\text {mon }}$ (free acids); (c) Asymmetric dimers, $\mathrm{C}=\mathrm{O}_{\text {asym; }}$ acting as hydrogen bond donors, $\mathrm{C}=\mathrm{O}_{\text {asymLow }}$, or attached to $\mathrm{O}-\mathrm{H}$ hydrogen bond donors, $\mathrm{C}=\mathrm{O}_{\text {asymHigh }}$ (d) Oligomers, catemer-like aggregates, $\mathrm{C}=\mathrm{O}_{\text {cat }}$. 
We have performed a semi-quantitative assessment of the relative amounts of each species present at a given temperature by performing a deconvolution of the carbonyl stretching band into six Gaussian peaks representing the different individual contributions of each species to the overall band shape, as described in detail elsewhere [42,48]. Representative examples of the fitted carbonyl regions obtained in each of the phases observed are shown in Figure 10. The stretching bands associated with the two types of carbonyl groups expected in the asymmetric dimers, $\mathrm{C}=\mathrm{O}_{\text {asym }}$, have been fitted to two bands, representing those participating as hydrogen bonding acceptors, $\mathrm{C}=\mathrm{O}_{\text {asymLow }}$, or attached to $\mathrm{O}-\mathrm{H}$ groups that are hydrogen bonded, $\mathrm{C}=\mathrm{O}_{\mathrm{asymHigh}}$. Figure 11a show the percentage of carbonyl groups involved in the various species as a function of temperature, and the relative amounts of each type of $\mathrm{H}$-bonded species scaled by the number of carbonyl groups in each species, respectively.

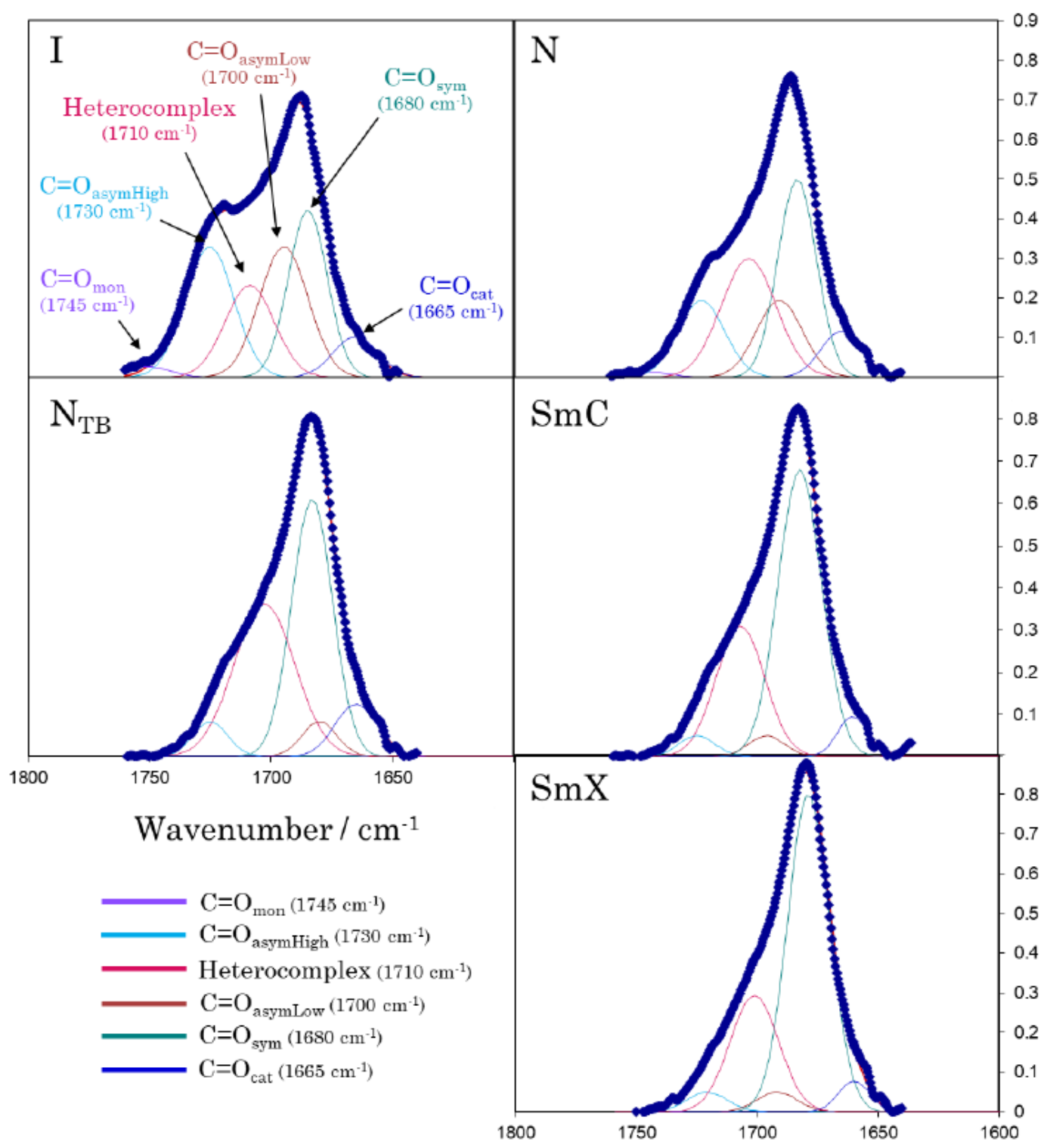

Figure 10. Deconvolution of the carbonyl stretching region for the CB6OBA:4OS equimolar mixture obtained in the isotropic $\left(195^{\circ} \mathrm{C}\right)$, nematic $\left(150^{\circ} \mathrm{C}\right)$, twist-bend nematic $\left(95^{\circ} \mathrm{C}\right)$, smectic $\mathrm{C}\left(80^{\circ} \mathrm{C}\right)$ and smectic $X\left(55^{\circ} \mathrm{C}\right)$ phases. 

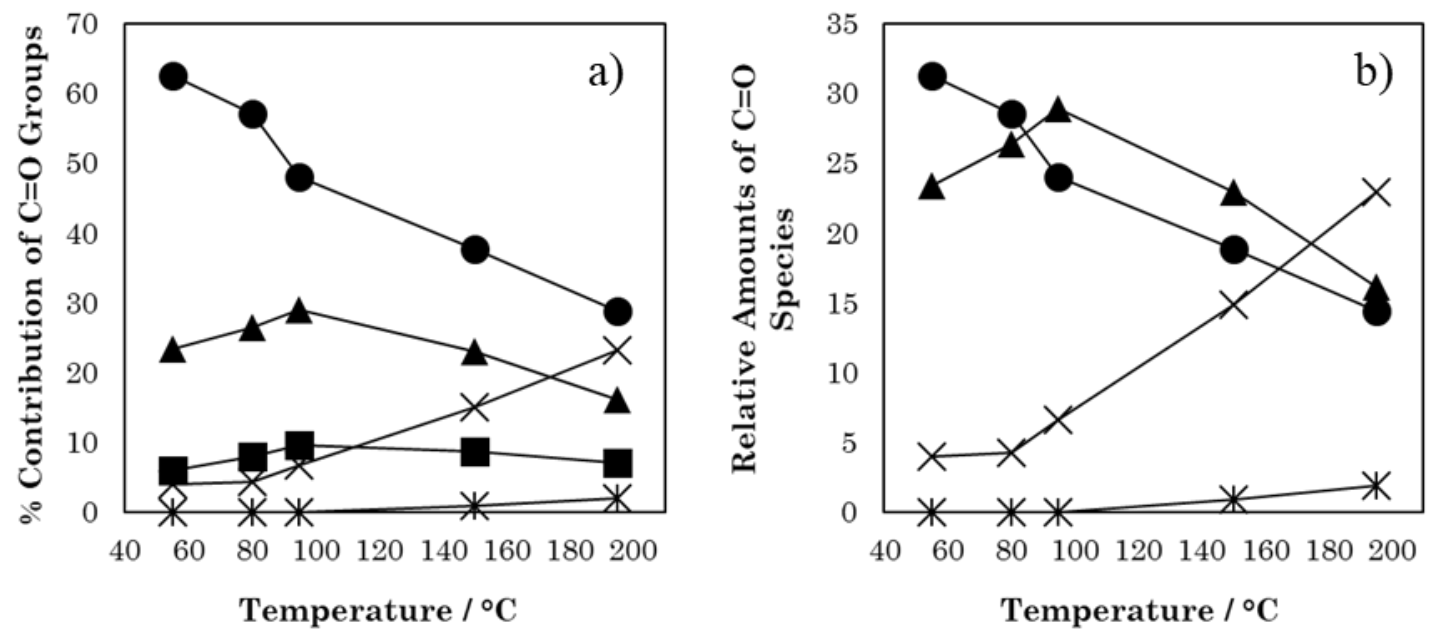

Figure 11. For the CB6OBA:4OS equimolar mixture, temperature dependence of (a) the relative areas obtained for the individual carbonyl groups involved in each type of species to the carbonyl stretching region and (b) the relative areas obtained for the different carbonyl-containing species to the carbonyl stretching region, scaled by the number of carbonyl groups. $*$ represents monomeric acid species, $\times$ asymmetric acid dimers, $\boldsymbol{\Delta}$ heterocomplexes, $\bullet$ symmetric acid dimers and $\boldsymbol{\square}$ catemers.

On cooling from the isotropic phase through the liquid crystal phases, the relative concentration of asymmetric acid dimers falls sharply, and this is mirrored by a rapid increase in the concentration of symmetric dimers, seen semi-quantitively in Figure 11b. The concentrations of the monomeric and catemeric acid species remain relatively constant across the whole temperature range. These observations are in accord with the behaviour of pure CB6OBA, as well as for other benzoic acid species $[33,48]$. The concentration of the heterocomplex in the isotropic phase is slightly greater than that of the symmetric acid dimer, and increases on cooling through the $\mathrm{N}$ and $\mathrm{N}_{\mathrm{TB}}$ phases. On further cooling into the smectic phases, there is a cross-over in the relative amounts of heterocomplex and symmetric acid dimer, and the most abundant carbonyl species is now the latter. It should be noted, however, that due to the highly monotropic nature of the lower temperature phases, it is not certain whether these IR measurements are taken in the smectic phases or if the sample has, at least partially, crystallised. Although it is evident that the CB6OBA: $n$ OS heterocomplex is present as a significant component in the mixture, it is clear that the pure CB6OBA asymmetric and symmetric acid dimers must also play an important role in determining the phase behaviour.

We now turn our attention to mixtures of the hydrogen bond acceptor CB6OBA with the hydrogen bond donors $1 \mathrm{OB} 6 \mathrm{OS}$ and $\mathrm{CB} 6 \mathrm{OS}[33,34]$, the transitional properties of these equimolar mixtures are listed Table 3. Both the CB6OBA:1OB6OS and CB6OBA:CB6OS supramolecular trimers were found to exhibit $\mathrm{N}$ and $\mathrm{N}_{\mathrm{TB}}$ phases. These were identified on the basis of characteristic optical textures: in a 1.6 micron planar-aligned cell a uniform nematic texture was observed with a high degree of Brownian motion, and a striped texture developed following the transition to the $\mathrm{N}_{\text {Tв }}$ phase, see Figure 12 .

Table 3. Transition temperatures and associated entropy changes for the supramolecular trimers CB6OBA:1OB6OS and CB6OBA:CB6OS. * Temperature obtained from DSC cooling trace.

\begin{tabular}{ccccccc}
\hline Complex & $\mathbf{T}_{\mathrm{Cr}-} /{ }^{\circ} \mathbf{C}$ & $\mathbf{T}_{\mathbf{N}_{\mathrm{TB}} \mathbf{N}} /{ }^{\circ} \mathbf{C}$ & $\mathbf{T}_{\mathrm{NI}} /{ }^{\circ} \mathbf{C}$ & $\Delta \mathbf{S}_{\mathrm{Cr}-} / \mathbf{R}$ & $\Delta \mathbf{S}_{\mathbf{N}_{\mathrm{TB}} \mathbf{N}} / \mathbf{R}$ & $\Delta \mathbf{S}_{\mathrm{NI}} / \mathbf{R}$ \\
\hline CB6OBA:1OB6OS & 140 & $142^{*}$ & 184 & 12.03 & 0.04 & 0.60 \\
CB6OBA:CB6OS & 127 & 143 & 186 & 12.34 & 0.07 & 1.24 \\
\hline
\end{tabular}



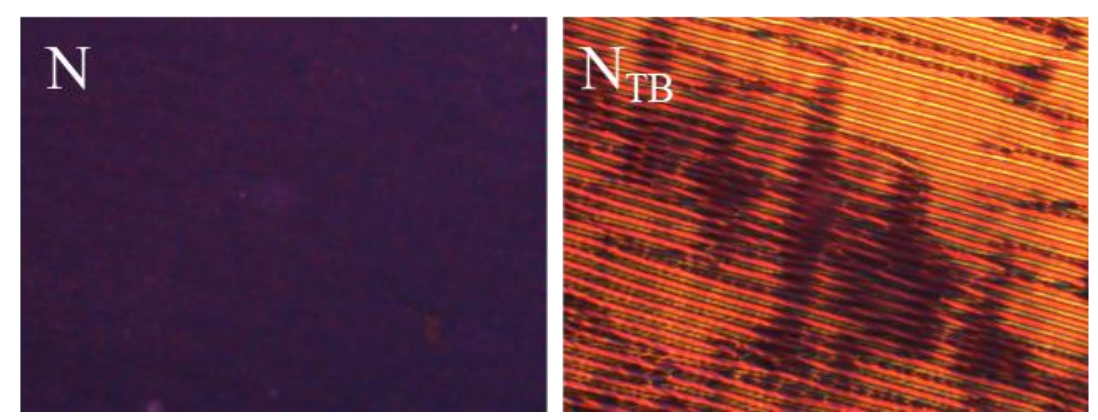

Figure 12. POM textures of the CB6OBA:1OB6OS mixture in the nematic phase (left) and twist-bend nematic phase (right).

The difference between these systems is the terminal group attached to the stilbazole-based hydrogen bond donor. Exchanging the nitrile for a methoxy group increases the melting point by $13 \mathrm{~K}$, and similar, but more pronounced, behaviour has been reported for conventional dimers containing these groups [11]. By comparison, $\mathrm{T}_{\mathrm{NI}}$ and $\mathrm{T}_{\mathrm{N}_{\mathrm{TB}} \mathrm{N}}$ are essentially the same for both mixtures, whereas for conventional dimers, the replacement of a methoxy group by a nitrile group leads to higher transition temperatures, and particularly, a higher $\mathrm{T}_{\mathrm{NI}}[11]$. The nitrile group is well-known to be more efficient at enhancing $\mathrm{T}_{\mathrm{NI}}$ than the methoxy group and this is attributed to both the change in shape on making this substitution and the tendency of cyanobiphenyls to self-organise in an antiparallel fashion. The smaller effects seen here on changing the terminal group in these longer complexes compared to those in dimers may be due to the dilution of these shape effects on increasing the overall complex length. It should be noted, however, that, as we have seen, the heterocomplex is present in a dynamic equilibrium with a range of other species and each will contribute to the transition temperature of the mixture.

\section{Conclusions}

We have reported a new series of supramolecular dimeric liquid crystals formed by hydrogen-bonding between unlike $\mathrm{H}$-bond donor and acceptors, CB6OBA and $n \mathrm{OS}(n=1-10)$, respectively. For small values of $n, \mathrm{~N}_{\mathrm{TB}}$ and $\mathrm{N}$ phases are seen. On increasing $n$ a series of smectic phases are observed on cooling the N phase. An FT-IR spectroscopic study confirms the formation of heterocomplexes between the unlike components in the mixtures but that these coexist with various acidic species in a complex equilibrium. Supramolecular trimers formed in CB6OBA:CB6OS and CB6OBA:1OB6OS mixtures, show $\mathrm{N}_{\mathrm{TB}}$ and $\mathrm{N}$ phases, and these represent the first hydrogen-bonded trimers consisting of unlike donor and acceptor fragments to do so.

Supplementary Materials: The following are available online at http:/www.mdpi.com/2073-4352/10/3/175/s1.

Author Contributions: R.W.: Investigation, Formal analysis, Validation, Visualisation, Writing-Original Draft, Writing-Reviewing and Editing. D.P.: Investigation, Formal analysis. A.M.-F.: Resources, Formal analysis. J.M.D.S.: Resources, Supervision. E.G.: Investigation, Formal analysis, Resources, Supervision. C.T.I.: Conceptualization, Supervision, Resources, Writing-Reviewing and Editing. All authors have read and agreed to the published version of the manuscript.

Funding: The work was supported by the National Science Centre (Poland) under the grant no. 2016/22/A/ST5/00319.

Acknowledgments: RW gratefully thanks the Carnegie Trust for the Universities of Scotland for the award of a PhD Scholarship (2015-2018).

Conflicts of Interest: The authors declare no conflict of interest.

\section{References}

1. Cestari, M.; Diez-Berart, S.; Dunmur, D.A.; Ferrarini, A.; de la Fuente, M.R.; Jackson, D.J.; Lopez, D.O.; Luckhurst, G.R.; Perez-Jubindo, M.A.; Richardson, R.M.; et al. Phase behavior and properties of the 
liquid-crystal dimer $1^{\prime \prime}, 7^{\prime \prime}$-bis(4-cyanobiphenyl-4'-yl) heptane: A twist-bend nematic liquid crystal. Phys. Rev. E Stat. Nonlinear Soft Matter Phys. 2011, 84, 031704. [CrossRef]

2. Meyer, R.B. Structural problems in liquid crystal physics. In Les Houches Summer School in Theoretical Physics; Molecular Fluids: Gordon and Bearch, New York, NY, USA, 1976; pp. 316-320.

3. Dozov, I. On the spontaneous symmetry breaking in the mesophases of achiral banana-shaped molecules. Europhys. Lett. 2001, 56, 247-253. [CrossRef]

4. Borshch, V.; Kim, Y.-K.; Xiang, J.; Gao, M.; Jákli, A.; Panov, V.P.; Vij, J.K.; Imrie, C.T.; Tamba, M.G.; Mehl, G.H.; et al. Nematic twist-bend phase with nanoscale modulation of molecular orientation. Nat. Commun. 2013, 4, 2635. [CrossRef]

5. Walker, R.; Pociecha, D.; Storey, J.; Gorecka, E.; Imrie, C.T. The Chiral Twist-Bend Nematic Phase (N*TB). Chem. A Eur. J. 2019, 25, 13329-13335. [CrossRef]

6. Walker, R.; Pociecha, D.; Strachan, G.; Storey, J.M.D.; Gorecka, E.; Imrie, C.T. Molecular curvature, specific intermolecular interactions and the twist-bend nematic phase: The synthesis and characterisation of the 1-(4-cyanobiphenyl-4'-yl)-6-(4-alkylanilinebenzylidene-4'-oxy)hexanes (CB6O.m). Soft Matter 2019, 15, 3188-3197. [CrossRef]

7. Salamończyk, M.; Vaupotič, N.; Pociecha, D.; Walker, R.; Storey, J.M.D.; Imrie, C.T.; Wang, C.; Zhu, C.; Gorecka, E. Multi-level chirality in liquid crystals formed by achiral molecules. Nat. Commun. 2019, 10, 1922. [CrossRef]

8. Abberley, J.P.; Killah, R.; Walker, R.; John, M.D.; Storey, C.T.; Imrie, M.S.; Zhu, C.; Gorecka, E.; Damian, P. Heliconical smectic phases formed by achiral molecules. Nat. Commun. 2018, 9, 228. [CrossRef]

9. Imrie, C.T.; Henderson, P.A. Liquid crystal dimers and higher oligomers: Between monomers and polymers. Chem. Soc. Rev. 2007, 36, 2096-2124. [CrossRef]

10. Imrie, C.T.; Henderson, P.; Yeap, G.-Y. Liquid crystal oligomers: Going beyond dimers. Liq. Cryst. 2009, 36, 755-777. [CrossRef]

11. Paterson, D.A.; Abberley, J.P.; Harrison, W.T.A.; Storey, J.; Imrie, C.T. Cyanobiphenyl-based liquid crystal dimers and the twist-bend nematic phase. Liq. Cryst. 2017, 44, 127-146. [CrossRef]

12. Mandle, R.J.; Davis, E.; Voll, C.-C.A.; Archbold, C.; Goodby, J.; Cowling, S. The relationship between molecular structure and the incidence of the NTB phase. Liq. Cryst. 2015, 42, 688-703.

13. Lu, Z.; Henderson, P.A.; Paterson, B.J.A.; Imrie, C.T. Liquid crystal dimers and the twist-bend nematic phase. The preparation and characterisation of the $\alpha, \omega$-bis(4-cyanobiphenyl-4'-yl) alkanedioates. Liq. Cryst. 2014, 41, 471-483. [CrossRef]

14. Cruickshank, E.; Salamończyk, M.; Pociecha, D.; Strachan, G.; Storey, J.M.D.; Wang, C.; Feng, J.; Zhu, C.; Gorecka, E.; Imrie, C.T. Sulfur-linked cyanobiphenyl-based liquid crystal dimers and the twist-bend nematic phase. Liq. Cryst. 2019, 46, 1595-1609. [CrossRef]

15. Šepelj, M.; Lesac, A.; Baumeister, U.; Diele, S.; Nguyen, H.L.; Bruce, D. Intercalated liquid-crystalline phases formed by symmetric dimers with an $\alpha, \omega$-diiminoalkylene spacer. J. Mater. Chem. 2007, 17, 1154-1165. [CrossRef]

16. Dawood, A.A.; Grossel, M.C.; Luckhurst, G.; Richardson, R.M.; Timimi, B.A.; Wells, N.J.; Yousif, Y.Z. On the twist-bend nematic phase formed directly from the isotropic phase. Liq. Cryst. 2016, 43, 2-12. [CrossRef]

17. Arakawa, Y.; Komatsu, K.; Tsuji, H. Twist-bend nematic liquid crystals based on thioether linkage. New J. Chem. 2019, 43, 6786-6793. [CrossRef]

18. Henderson, P.A.; Imrie, C.T. Methylene-linked liquid crystal dimers and the twist-bend nematic phase. Liq. Cryst. 2011, 38, 1407-1414. [CrossRef]

19. Paterson, D.; Walker, R.; Abberley, J.P.; Forestier, J.; Harrison, W.T.A.; Storey, J.M.D.; Pociecha, D.; Gorecka, E.; Imrie, C.T. Azobenzene-based liquid crystal dimers and the twist-bend nematic phase. Liq. Cryst. 2017, 44, 2060-2078. [CrossRef]

20. Abberley, J.P.; Storey, J.M.D.; Imrie, C.T. Structure-property relationships in azobenzene-based twist-bend nematogens. Liq. Cryst. 2019, 42, 2102-2114. [CrossRef]

21. Abberley, J.P.; Jansze, S.; Walker, R.; Paterson, D.; Henderson, P.; Marcelis, A.T.M.; Storey, J.M.D.; Imrie, C.T. Structure-property relationships in twist-bend nematogens: The influence of terminal groups. Liq. Cryst. 2017, 44, 68-83. [CrossRef]

22. Paterson, D.; Crawford, C.A.; Pociecha, D.; Walker, R.; Storey, J.M.; Gorecka, E.; Imrie, C.T. The role of a terminal chain in promoting the twist-bend nematic phase: The synthesis and characterisation of the 
1-(4-cyanobiphenyl-4'-yl)-6-(4-alkyloxyanilinebenzylidene-4'-oxy) hexanes. Liq. Cryst. 2018, 45, 2341-2351. [CrossRef]

23. Zhang, Z.; Panov, V.P.; Nagaraj, M.; Goodby, J.; Luckhurst, G.R.; Gleeson, H.; Mandle, R.J.; Jones, J.C. Raman scattering studies of order parameters in liquid crystalline dimers exhibiting the nematic and twist-bend nematic phases. J. Mater. Chem. C 2015, 3, 10007-10016. [CrossRef]

24. Sreenilayam, S.; Panov, V.P.; Vij, J.K.; Shanker, G. The NTB phase in an achiral asymmetrical bent-core liquid crystal terminated with symmetric alkyl chains. Liq. Cryst. 2017, 44, 244-253. [CrossRef]

25. Tamba, M.G.; Baumeister, U.; Pelzl, G.; Weissflog, W. Banana-calamitic dimers: Further variations of the bent-core mesogenic unit. Ferroelectrics 2014, 468, 52-76. [CrossRef]

26. Mandle, R.J.; Goodby, J. A Liquid Crystalline Oligomer Exhibiting Nematic and Twist-Bend Nematic Mesophases. ChemPhysChem 2016, 17, 967-970. [CrossRef]

27. Simpson, F.P.; Mandle, R.J.; Moore, J.N.; Goodby, J. Investigating the Cusp between the nano- and macro-sciences in supermolecular liquid-crystalline twist-bend nematogens. J. Mater. Chem. C 2017, 5, 5102-5110. [CrossRef]

28. Tuchband, M.; Paterson, D.; Salamończyk, M.; Norman, V.A.; Scarbrough, A.N.; Forsyth, E.; Garcia, E.; Wang, C.; Storey, J.M.D.; Walba, D.M.; et al. Distinct differences in the nanoscale behaviors of the twist-bend liquid crystal phase of a flexible linear trimer and homologous dimer. Proc. Natl. Acad. Sci. USA 2019, 166, 10698-10704. [CrossRef]

29. Mandle, R.J.; Goodby, J. A novel nematic-like mesophase induced in dimers, trimers and tetramers doped with a high helical twisting power additive. Soft Matter 2018, 14, 8846-8852. [CrossRef]

30. Mandle, R.J.; Goodby, J.W. A Nanohelicoidal Nematic Liquid Crystal Formed by a Non-Linear Duplexed Hexamer. Angew. Chem. Int. Ed. 2018, 57, 7096-7100. [CrossRef]

31. Stevenson, W.D.; An, J.; Zeng, X.; Xue, M.; Zou, H.-X.; Liu, Y.; Ungar, G. Twist-bend nematic phase in biphenylethane-based copolyethers. Soft Matter 2018, 14, 3003-3011. [CrossRef]

32. Greco, C.; Luckhurst, G.R.; Ferrarini, A. Enantiotopic discrimination and director organization in the twist-bend nematic phase. Phys. Chem. Chem. Phys. 2013, 15, 14961-14965. [CrossRef] [PubMed]

33. Jansze, S.M.; Martínez-Felipe, A.; Storey, J.M.D.; Marcelis, A.T.M.; Imrie, C.T. A twist-bend nematic phase driven by hydrogen bonding. Angew. Chem. Int. Ed. 2015, 54, 643-646. [CrossRef]

34. Walker, R.; Pociecha, D.; Abberley, J.P.; Martinez-Felipe, A.; Paterson, D.; Forsyth, E.; Lawrence, G.B.; Henderson, P.; Storey, J.M.D.; Gorecka, E.; et al. Spontaneous chirality through mixing achiral components: A twist-bend nematic phase driven by hydrogen-bonding between unlike components. Chem. Commun. 2018, 54, 3383-3386. [CrossRef] [PubMed]

35. Walker, R.; Pociecha, D.; Crawford, C.; Storey, J.; Gorecka, E.; Imire, C. Hydrogen bonding and the design of twist-bend nematogens. J. Mol. Liq. 2020. [CrossRef]

36. Paterson, D.A.; Gao, M.; Kim, Y.-K.; Jamali, A.; Finley, K.L.; Robles-Hernández, B.; Diez-Berart, S.; Salud, J.; de la Fuente, M.R.; Timimi, B.A.; et al. Understanding the twist-bend nematic phase: The characterisation of 1-(4-cyanobiphenyl-4'-yloxy)-6-(4-cyanobiphenyl-4'-yl)hexane (CB6OCB) and comparison with CB7CB. Soft Matter 2016, 12, 6827-6840. [CrossRef]

37. Kato, T.; Frechet, J. New Approach to Mesophase Stabilization through Hydrogen-Bonding Molecular Interactions in Binary Mixtures. J. Am. Chem. Soc. 1989, 111, 8533-8534. [CrossRef]

38. Al-Janabi, A.; Mandle, R.J.; Goodby, J. Isomeric trimesogens exhibiting modulated nematic mesophases. RSC Adv. 2017, 7, 47235-47242. [CrossRef]

39. Mandle, R.J.; Stevens, M.P.; Goodby, J.W. Developments in liquid-crystalline dimers and oligomers. Liq. Cryst. 2017, 44, 2046-2059. [CrossRef]

40. El Sayed, S.; De La Torre, C.; Santos-Figueroa, L.E.; Martínez-Máñez, R.; Sancenón, F.; Orzaez, M.; Costero, A.M.; Parra, M.; Gil, S. 2,4-Dinitrophenyl Ether-Containing Chemodosimeters for the Selective and Sensitive in Vitro and in Vivo Detection of Hydrogen Sulfide. Supramol. Chem. 2015, 27, 244-254. [CrossRef]

41. Marquardt, D.W.; Mathematics, A. An Algorithm for Least-Squares Estimation of Nonlinear Parameters. J. Soc. Ind. Appl. Math. 1963, 11, 431-441. [CrossRef]

42. Paterson, D.; Martinez-Felipe, A.; Jansze, S.; Marcelis, A.T.; Storey, J.M.; Imrie, C.T. New insights into the liquid crystal behaviour of hydrogen-bonded mixtures provided by temperature-dependent FTIR spectroscopy. Liq. Cryst. 2015, 42, 928-939. [CrossRef] 
43. Odinokov, S.; Iogansen, A. Torsional $\gamma(\mathrm{OH})$ vibrations, Fermi resonance $[2 \gamma(\mathrm{OH}) \Leftarrow v(\mathrm{OH})]$ and isotopic effects in i.r. spectra of $\mathrm{H}$-complexes of carboxylic acids with strong bases. Spectrochim. Acta Part A Mol. Spectrosc. 1972, 28, 2343-2350. [CrossRef]

44. Lee, J.; Painter, P.; Coleman, M. Hydrogen Bonding in Polymer Blends. 4. Blends Involving Polymers Containing Methacrylic Acid and Vinylpyridinegroups. Macromolecules 1988, 21, 954-960. [CrossRef]

45. Martinez-Felipe, A.; Cook, A.G.; Abberley, J.P.; Walker, R.; Storey, J.M.D.; Imrie, C.T. An FT-IR spectroscopic study of the role of hydrogen bonding in the formation of liquid crystallinity for mixtures containing bipyridines and 4-pentoxybenzoic acid. RSC Adv. 2016, 6, 108164-108179. [CrossRef]

46. Martinez-Felipe, A.; Brebner, F.; Zaton, D.; Concellon, A.; Ahmadi, S.; Piñol, M.; Oriol, L. Molecular recognition via hydrogen bonding in supramolecular complexes: A Fourier transform infrared spectroscopy study. Molecules 2018, 23, 2278. [CrossRef] [PubMed]

47. Martinez-Felipe, A.; Imrie, C.T. The role of hydrogen bonding in the phase behaviour of supramolecular liquid crystal dimers. J. Mol. Struct. 2015, 1100, 429-437. [CrossRef]

48. Abdy, M.J.; Murdoch, A.; Martinez-Felipe, A. New insights into the role of hydrogen bonding on the liquid crystal behaviour of 4-alkoxybenzoic acids: A detailed IR spectroscopy study. Liq. Cryst. 2016, 43, 2191-2207. [CrossRef]

(C) 2020 by the authors. Licensee MDPI, Basel, Switzerland. This article is an open access article distributed under the terms and conditions of the Creative Commons Attribution (CC BY) license (http://creativecommons.org/licenses/by/4.0/). 